\title{
E08
}

\section{Near Surface Variations and its Impact on Seismic Repeatability at Naylor Field, Australia}

\author{
Y.Y.M. Al Jabri* (Petroleum Development Oman), C. Dupuis (Curtin \\ University) \& M. Urosevic (Curtin University)
}

\section{SUMMARY}

The micro-array investigation of the near-surface layers at Naylor site indicated that the velocities and Qfactor have same directional variations at this site. The first $0.5 \mathrm{~m}$ layer of the agricultural soil (elastoplastic zone) has a low velocity and low Q-factor, hence this zone significantly attenuated seismic energy. Micro-VSP measurements show a consistence increase in velocity with depth and no seismic anisotropy. The change in the water saturation in near surface can cause the changes in velocity and attenuation. Around $30 \%$ of RMS amplitude difference can be measured at the reservoir level from the simulated models and that is by simulating the measured parameters of the near surface properties of wet and dry conditions of the near surface with no change in the reservoir properties. 


\section{Introduction}

In the case of the Naylor $\mathrm{CO}_{2}$ injection test site area, the presence of sinkholes and karst topography in the near surface zone make seismic non-repeatability investigations not only necessary but also interesting (Figure 2). In such geological terrane, the degree of signal scattering caused by a rugose limestone surface and caverns may depend on the depth of the water table. Consequently, to test such possibility, repeated 2D seismic test lines have been acquired at Naylor location prior to 3D baseline seismic surveys (Figure 1). These seismic lines were recorded with a Mini-Vibroseis and WeightDrop source in both wet and dry conditions. The aim of this work was to assess non-repeatability due to the source type change and variations in soil conditions; that is saturation (Urosevic et al., 2008). To help understand field observations we conducted these near-surface measurements to determine the variation of elastic properties of the near-surface layer with different seasons. Baker et al. (1997) and Jefferson et al. (1998) observed over periods of days to weeks that short-term saturation variations in near surface could have a significant impact on the quality and character of shallow seismic reflection data. Analysing the changes in attenuation (absorption and scattering) and the propagation velocity in the upper $4 \mathrm{~m}$ of the near surface at the Naylor Field site could give us additional clues which may be important additional for 4D analyses. The aim of this work was to analyse the effect of the variation in the water saturation in the first few metres of the near surface on the seismic signals and to understand the effects of variable near surface conditions on time-lapse seismic surveys. In particular, we investigate the variation of elastic properties of both top soil and the deeper rugose clay-limestone interface as function of soil saturation. Such measurements effectively evaluate in situ repeatability that is 4D seismic effects produced by seasonal variations that is changes of elastic properties due to variations of water table depth. High seismic repeatability is critical to the monitoring program of the Naylor Field because of the small time-lapse effect related to $\mathrm{CO}_{2}$ injection into a depleted gas reservoir (Naylor). To understand the effect of ground conditions and improve repeatability, I conducted a so-called "micro-array" investigation of the near-surface layers at this site.

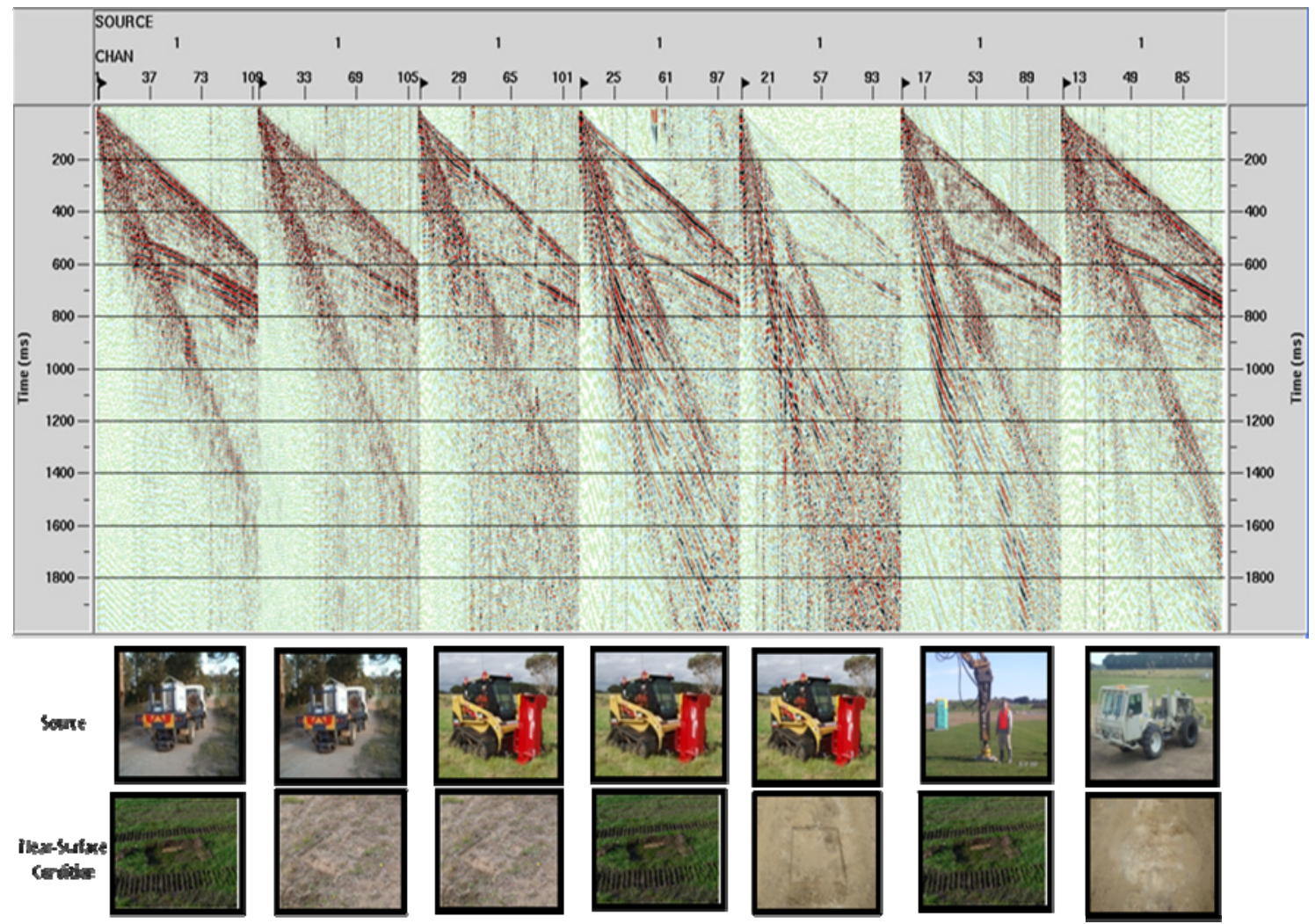

Figure 1 The first shot gather of the six selected repeated 2D seismic test lines which has been acquired at the same place using different seismic sources and during different near-surface conditions. The both pictures of seismic source and near-surface conditions correspond to the seismic shot gather data in the same column. 


\section{Methodology}

It is anticipated that the non-repeatability issues are, to the first order of approximation, related to variations of the properties of the top soil and underlying clay/limestone units. To analyze the effects of variable near surface conditions on time-lapse seismic surveys, we acquired seismic refraction survey lines at three different directions as well as a Reversed VSP and ultrasonic measurements (Figure 3). We acquired core samples to measure the P-wave velocity, amplitudes, Q-absorption (proxy is peak frequency) during the wet and dry conditions of the near surface. The three refraction and reflection lines were $27 \mathrm{~m}$ long and oriented at azimuth $30^{\circ}$ for line $\mathrm{A}, 90^{\circ}$ for line $\mathrm{B}$ and $150^{\circ}$ for line $\mathrm{C}$ from the North direction which was the minimum horizontal stress direction. A total of 24 shot stations deployed along every refraction seismic line with $1 \mathrm{~m}$ spacing intercepted each other at the middle of each line. The seismic source used for the refraction seismic surveys was a $4.5 \mathrm{~kg}$ Sledge Hammer and explosive charge for the Reversed VSP. There were 5 shot positions of each line of the refraction lines (two from each end of the line with offset $1.5 \mathrm{~m}$ and $0.5 \mathrm{~m}$, and one in the middle of the line). For the Reversed VSP, we used the same borehole where we extracted our core sample. We used detonators by shooting at the borehole starting from a depth of $1.9 \mathrm{~m}$ up to $0.2 \mathrm{~m}$ with $10 \mathrm{~cm}$ spacing. The shots were recorded using the 24 channels of refraction line A with azimuth $30^{\circ}$ from the north. All data was recorded with a trace length of $200 \mathrm{~ms}$ and sample rate of $0.125 \mathrm{~ms}$. Core samples were collected at the site and wrapped very quickly with plastic food wrap to prevent the samples from the drying and to keep the moisture content in the samples ready for comparative in-situ measurements. Finally, numerical tests were performed by using the calibrated soil parameters, logs data, cores and surface seismic measurements.

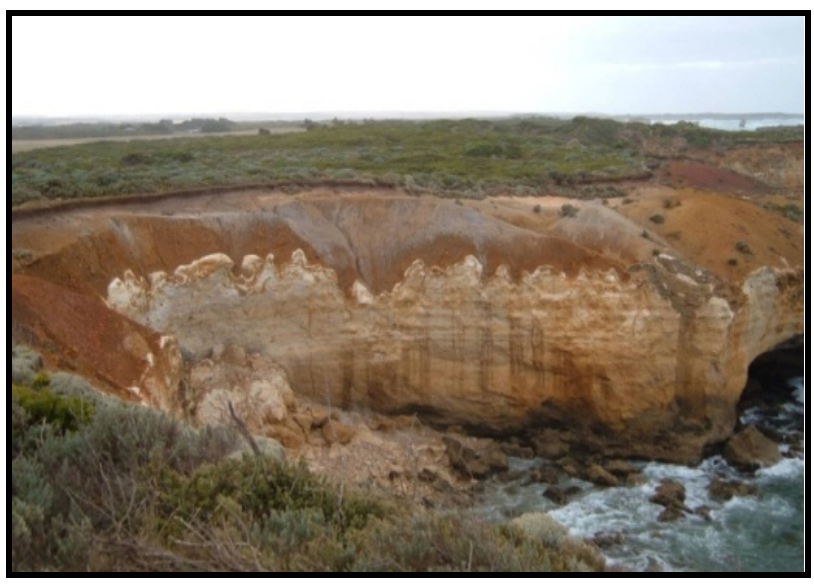

Figure $2 \mathrm{~A}$ cliff $4 \mathrm{~km}$ from the Naylor Field, the first layer is a clay layer of 3-4 m thickness which overlies a limestone layer. The limestone layer has a corrugated top surface.

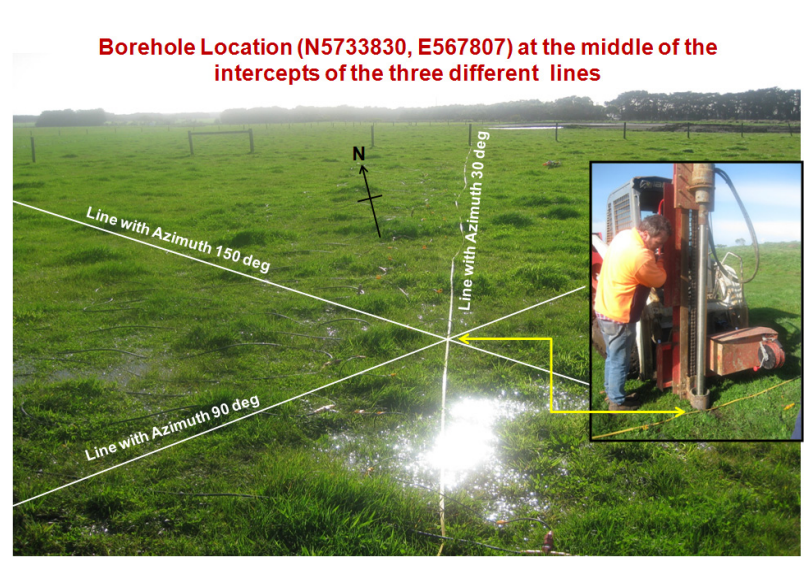

Figure 3 The geometry utilised for refraction and VSP surveys.

\section{Analysis and Results}

Refraction data analyses was carried out to calculate the P-wave velocities and absorption for the top $4 \mathrm{~m}$ of the near surface with three different azimuths. The velocities and Q-Absorption have been calculated using the three different refraction lines for studying the property changes at the near surface in different direction. The Q-factor was calculated using the pulse rise time method. The results of these calculations showed that there is a consistent increase in velocity and Q-factor with depth in the all three directions and the average of these measurements showed in (Figure 6). The RMS amplitude of the first arrival has been measured at the middle receiver from six different shots at different azimathal direction around the borehole during the wet and dry conditions of the near surface. Figure 5 represents the change in amplitude due the change in the water saturation during the wet and dry conditions of the near surface. The average velocities were also measured from each shots of the Micro array VSP at every receiver location. The average velocity is increasing with depth and during wet condition of the near surface the average velocity higher comparing to the dry condition of the near surface (Figure 4). Information from near surface measurements, logs data, cores and surface 


\section{Near Surface}

seismic measurements were used as input for the simulations (Figure 6). The comparison between the results of the simulated seismic data between wet and dry near surface showing that the RMS amplitude difference is at the Top Clifton formation about 30\% (Figure 7). This change, which does not represent the change in reservoir properties due to $\mathrm{CO} 2$ injection, is caused only by the change in the water variation during the wet and dry conditions of the near surface.

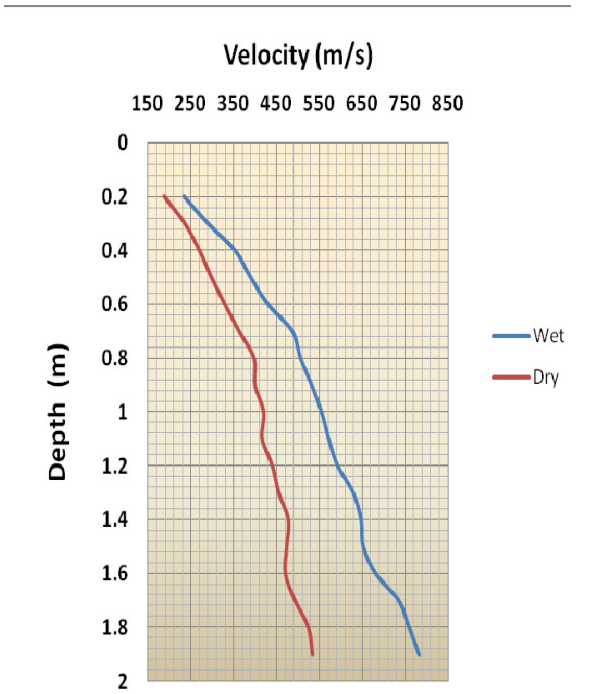

Figure 4 This graph shows the change in the average velocity with depth which has been measured from the reversed wake-away VSP at a reciver with $0.5 \mathrm{~m}$ from the borehole during the wet and dry conditions of the near surface.

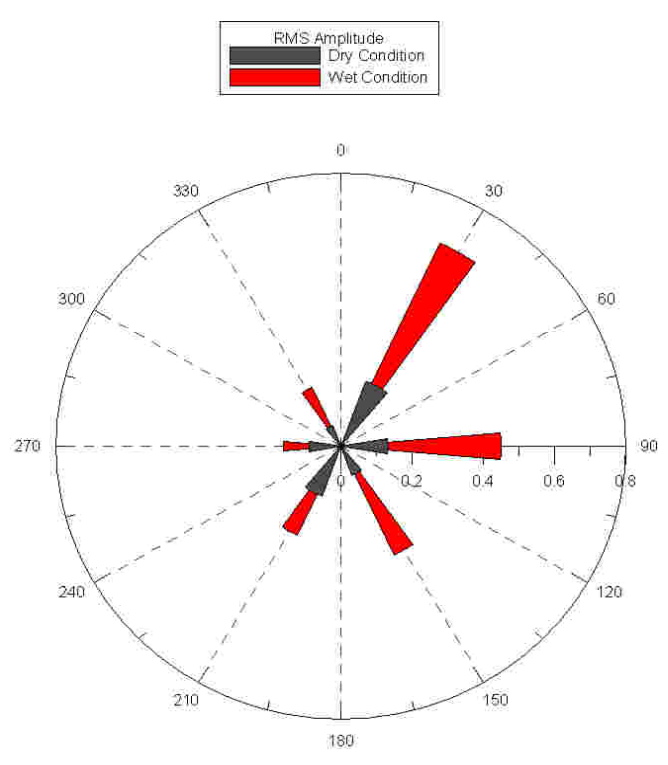

Figure 5 The results of the RMS amplitude measured at the mei-reciver from six different azimithal direction around the bourhole during the wet and dry conditions is representing the the change in amplitude due to the change in water saturation and the different location.

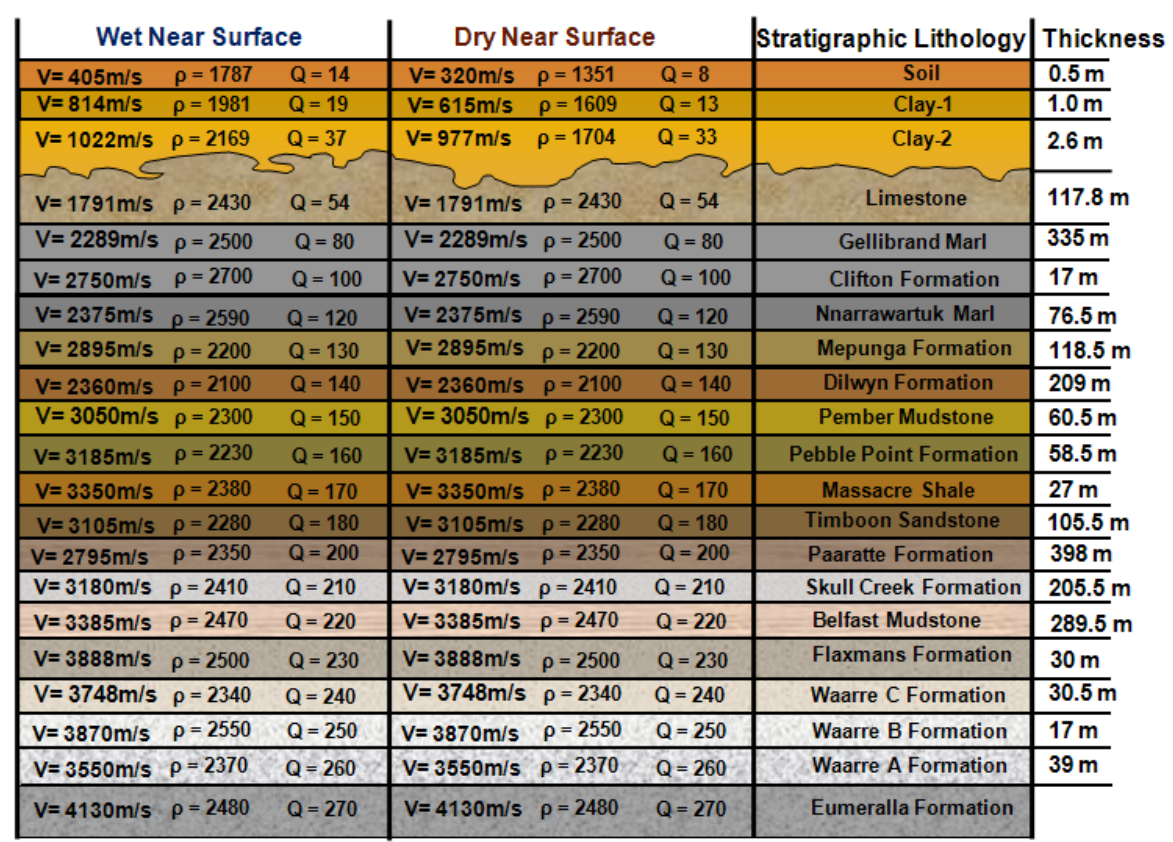

Figure 6 Carton model for Naylor Field case which represents the propeties change of the first three layers of the nearsurface during the wet and dry conditions. 


\section{Near Surface}

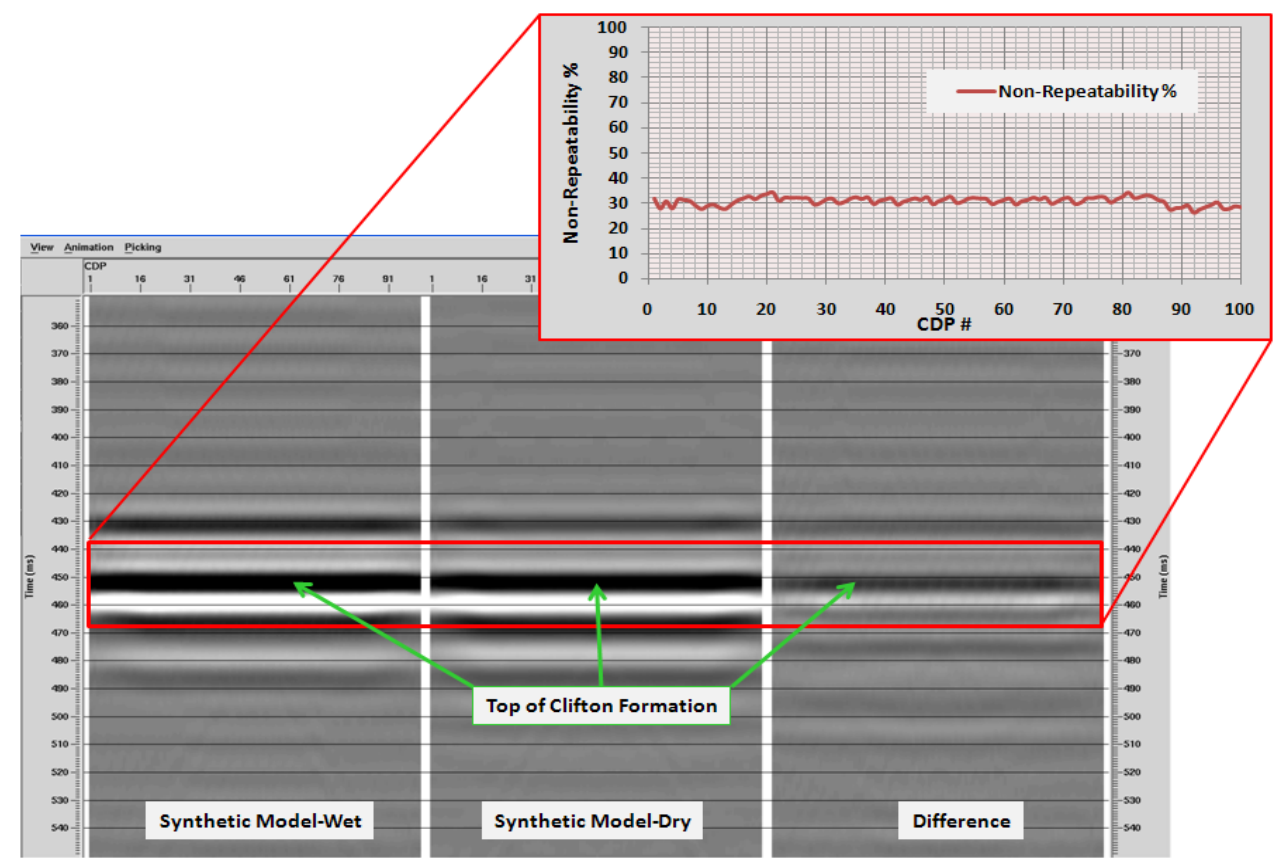

Figure 7 A comperison between the synthetich seimic models of wet and dry near surface and their difrences. The top graph is shows the non-repeatability curve computed for wet and dry case for a time window of $40 \mathrm{~ms}$ around the Clifton Formation.

\section{Conclusion}

The micro-array investigation of the near-surface layers at Naylor site indicated that the velocities and Q-factor have same directional variations at this site. The first $0.5 \mathrm{~m}$ layer of the agricultural soil (elasto-plastic zone) has a low velocity and low Q-factor, hence this zone significantly attenuated seismic energy. Micro-VSP measurements show a consistence increase in velocity with depth and no seismic anisotropy. The change in the water saturation in near surface can cause the changes in velocity and attenuation. Around $30 \%$ of RMS amplitude difference can be measured at the reservoir level from the simulated models and that is by simulating the measured parameters of the near surface properties of wet and dry conditions of the near surface with no change in the reservoir properties.

\section{Acknowledgements}

This work is sponsored by CO2CRC and we thank S. Sharma and A. Kepic for making these experiments possible. We are grateful to our colleagues from Curtin University C. Dupuis and A. Dzunic for motivating discussions and help with data acquisition. We thank Jalila Al Riyami and Paul Zwartjes for the editing process.

\section{References}

Al-Jabri Y., Urosevic M., and Kepic A., 2008, The effects of the near-surface weathered zone on the $\mathrm{CO} 2$ time-lapse monitoring program at Naylor-1, CO2CRC Otway Project, Victoria, Australia: CO2CRC Symposium 2008, Queenstown, New Zealand, 1 - 5 December 2008.

Baker, G.S., Steeples, D.W. and Feroci, M., 1997, The time dependence of shallow reflection data: Leading Edge 16, 1663.1666.

Blair D. P., and A. T. Spathis, 1982, Attenuation of explosion-generated pulse in rock masses: Journal of Geophysical Research, 87, 3885-3892

Jefferson, R.D., Steeples, D.W., Black, R.A. and Carr, T., 1998, Effects of soil-moisture content on shallow-seismic data: Geophysics 63, 1357.1362.

Urosevic, M., Sherlock D., Kepic, A., Nakanishi S. and Tcherkashnev S., K., 2008, Time lapse VSP program for Otway basin CO2 sequestration pilot project", 70th EAGE Conference \& Exhibition, Rome, Italy. 